\title{
A Case of Ectopic Hamartomatous Thymoma Occurring in the Neck
}

\author{
Yasuhiko Tanaka ${ }^{1 / 2)}$, Shigeki Sato ${ }^{3)}$, Hideo Tomisawa ${ }^{4)}$, \\ Manabu Nakamura ${ }^{15)}$, Masahiko Fukasawa ${ }^{1)}$ and Izumi Koizuka ${ }^{1)}$
}

Ectopic hamartomatous thymomas (EHT) is an extremely rare disorder.

We report herein on a case of EHT occurring in the neck with a review of the literature. A 35-yearold man first noticed a swelling in his left cervical region at the beginning of March, 2005, and he came for a checkup in our department in March. In the initial examination, palpation revealed a $3 \times 5 \mathrm{~cm}$ soft mass with a somewhat indistinct border in the left supraclavicular area. There was no subjective symptom except swelling, and palpation revealed no anomaly in the cervical lymph nodes, and no other lesion was seen in the head and neck area.

A tumor was present between the sternocleidomastoid muscle and the left lobe of the thyroid gland, and the MRI imaging did not show any involvement of the thyroid gland.

We performed a tumorectomy under general anesthesia. There was a tumor right under the sternocleidomastoid, there was no adhesions seen at the periphery of the tumor, and tumor removal went smoothly. The histological diagnosis was an ectopic hamartomatous thymoma.

In 1984, Rosai et al. proposed the concept of the EHT as a lesion having the character of both a hamartoma and a tumor also comprising cervical ectopic thymic tissue. No recurrence has been reported in cases where the tumor has been totally extirpated. In our present case, no recurrence has been seen in a 7 -year postoperative follow-up.

Keywords : ectopic hamartomatous thymoma, diagnosis, neck tumor

\section{References}

1) Rosai J, Limas C and Husband EM : Ectopic hamartomatous thymoma. A distinctive benign lesion of lower neck. Am J Surg Pathol 8: 501-513, 1984.

2) Fetsch JF, Laskin WB, Michal M, et al. : Ectopic hamartomatous thymoma: a clinicopathologic and immunohistochemical analysis of 21 cases with data supporting reclassification as a branchial anlage mixed tumor. Am J Surg Pathol 28: 13601370, 2004.

3) Sakurai H, Kaji M, Mukai K, et al. : Ectopic hamartomatous thymoma - a truly rare neoplasm: report of a case. Surg Today 40: 146-149, 2010.

4) Kazakov DV, Mukensnabl P, Hes O, et al. : 'Ectopic' ectopic hamartomatous thymoma. Histopathology 45: 202-204, 2004.

5) Hirokawa M, Tadaoka Y, Shimizu M, et al. : Ectopic hamar- tomatous thymoma. Report of a case with fine needle aspiration biopsy findings. Acta Cytol 43: 232-234, 1999.

6) Choi JH, Shim YR and Song SY : Fine needle aspiration cytology of ectopic hamartomatous thymoma. Acta Cytol 51: 672675,2007

7) Iida E, Okazaki M, Sarukawa S, et al. : Ectopic hamartomatous thymoma growing in the sternocleidomastoid muscle masquerading as sarcoma. Scand J Plast Reconstr Surg Hand Surg 40: 249-252, 2006.

8）岩田 純：異所性過誤腫性胸腺腫 Ectopic hamartomatous thymoma. 病理と臨床 21: 662-663, 2003.

9) Armour A and Williamson JM : Ectopic cervical hamartomatous thymoma showing extensive myoid differentiation. J Laryngol Otol 107: 155-158, 1993.

10) Shim DB, Song JS and Baek SJ : An ectopic hamartomatous thymoma. Auris Nasus Larynx 39: 110-113, 2012.

1) Department of Otolaryngology, St. Marianna University School of Medicine

2) Department of Otolaryngology, Yokohama General Hospital

3) Kuzugaya Koma Clinic

4) Shinjuku Tomisawa Clinic

5) Department of Otolaryngology, Kawasaki Municipal Tama Hospital

Corresponding Author Address : Yasuhiko Tanaka yasu-t@marianna-u.ac.jp 


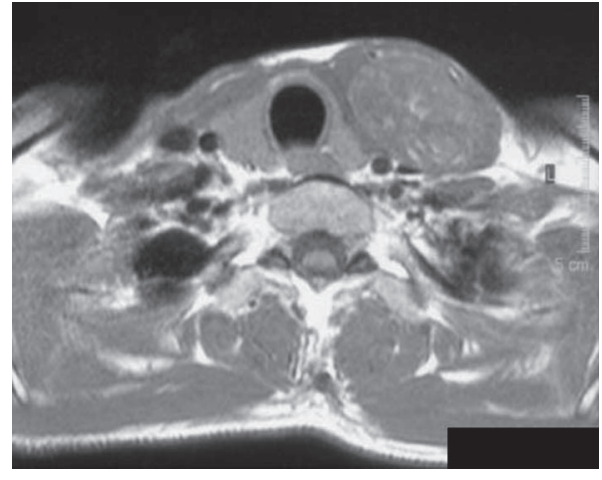

a

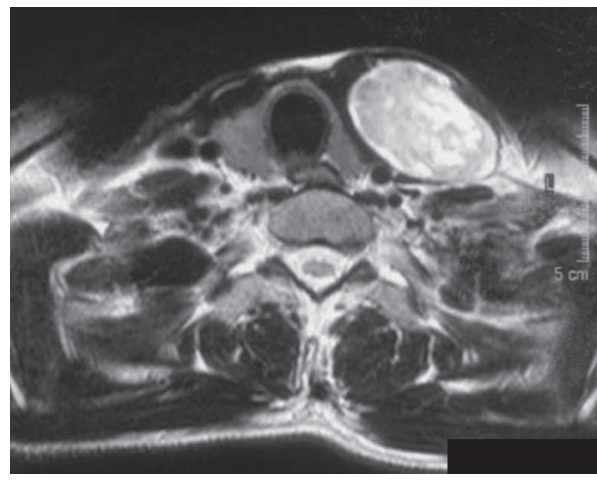

C

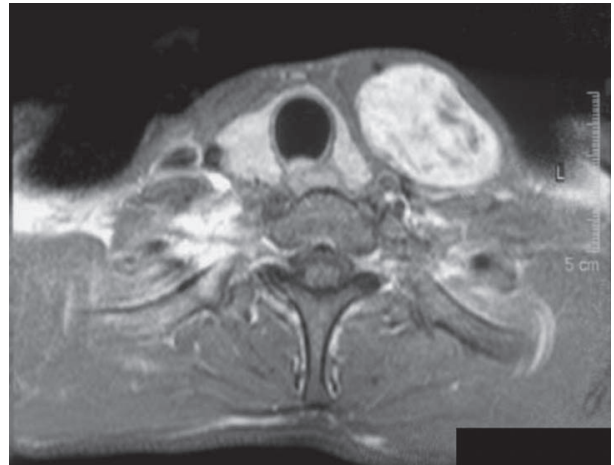

b

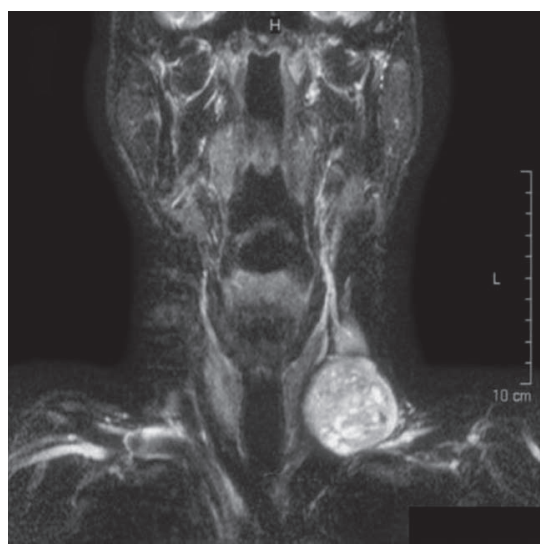

d

Preoperative neck MRI

A T1- weighted image revealed an isointense signal with partial high signal intensity inside, whereas T1-weighted imaging with gadolinium contrast showed up more strongly, thus demonstrating a clear margin and partly heterogenous signal intensity inside. A T2-weighted image indicated a clearly bordered high signal intensity, partly heterogeneous inside. STIR as well showed a high signal intensity which was partly heterogeneous inside.

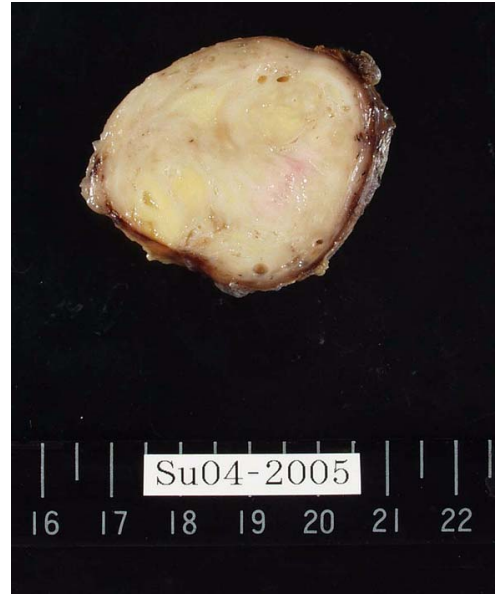

Gross findings of the tumor

The extirpated tumor was $4 \times 3.5 \mathrm{~cm}$. The color of the incised surface was grayish white, and was partly yellowish white inside, with coexistence of the solid part, cystic region and viscous liquid region.

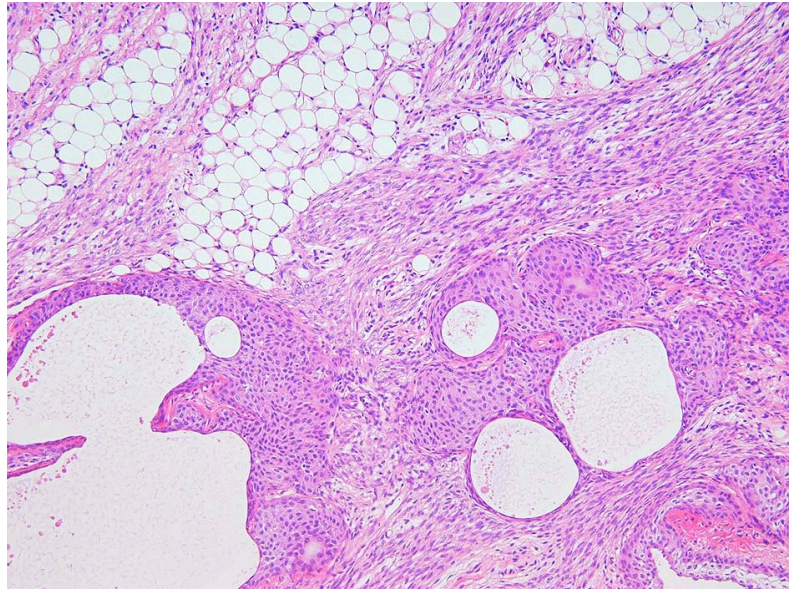

Pathological findings

We found non-atypical fusiform cells and island-forming epidermal cells along with adipose cells. Literally, as well, we diagnosed EHT which characteristically coexists with these cells. 